\title{
Contribuição da Web 2.0 como ferramenta de aprendizagem: um estudo de caso
}

Bruno Silva Leite

Marcelo Brito Carneiro Leão

\section{Resumo}

Este trabalho tem como propósito de analisar e avaliar a utilização de alguns recursos da Web 2.0, e como esses estão sendo inseridos no ensino das ciências. Apresentamos um estudo sobre uma experiência em que um grupo de alunos trabalhou com algumas ferramentas da Web 2.0 durante uma disciplina de Química, envolvendo a temática de ligações Químicas. Nosso objetivo foi de analisar o papel de algumas ferramentas da Web 2.0 e como estas poderiam contribuir para uma aprendizagem ampla e flexível por parte desses usuários. Utilizamos também para fins desta investigação, a observação de um grupo de alunos que não se utilizaram dessas ferramentas, visando uma comparação com o grupo de usuários Web 2.0. Dentre os resultados obtidos, ressaltamos o potencial de ajuda das ferramentas Web 2.0, descrita pelos alunos. Observamos também a importância da incorporação da Teoria da Flexibilidade Cognitiva e da Teoria dos Construtos Pessoais em ambiente Web 2.0 para a construção de uma aprendizagem mais flexível.

Palavras-chave: Web 2.0, Teoria da Flexibilidade Cognitiva, Teoria dos Construtos Pessoais, Ensino de ciências, Ensino e Aprendizagem 2.0.

Abstract

\section{Contribution of Web 2.0 as a Learning Tool: Case Study}

This paper proposes analyses and evaluates the use of Web 2.0 some features and how these are being included in science teaching. We present a study on an experiment in which a group of students worked with some Web 2.0 tools for a discipline of chemistry, involving the theme: Chemical bonds. Our aim was to analyse the role of some Web 2.0 tools in chemistry teaching and how these can influence in the learning flexible and free from these users. We also use for purposes of this research, observation of a group of students who did not used these tools, aiming a comparison with the users group Web 2.0. The results showed students highlighted the educational potential of Web 2.0 tools, as well as the importance of incorporating Cognitive Flexibility Theory and Personal Constructs Theory in Web 2.0 environments.

Keywords: Web 2.0, Cognitive Flexibility Theory, Personal Constructs Theory, Science Teaching, Teaching and Learning 2.0. 


\section{Introdução}

Este artigo é uma parte dos resultados de uma pesquisa de mestrado, com dissertação defendida no programa de Pós-Graduação em Ensino de Ciências da Universidade Federal Rural de Pernambuco (UFRPE), cujo objetivo foi investigar as contribuições do uso de ferramentas da Web 2.0 no Ensino de Química.

O conceito de Tecnologia da Informação e da Comunicação (TIC) é utilizado para expressar a convergência entre a informática e as telecomunicações. As TIC agrupam ferramentas informáticas e comunicativas como: televisão, vídeo, rádio, Internet etc. Todas essas tecnologias têm em comum a utilização de meios comunicativos que facilitam a difusão da informação. Além disso, as TIC exigem uma formação permanente do cidadão para desenvolver tanto pessoal como profissionalmente ao longo de toda sua vida (LARA, 2009).

Percebe-se que a cada dia mais as Tecnologias da Informação e da Comunicação (TIC) são incorporadas como recursos didáticos ao processo de ensino e aprendizagem. Entretanto, esta utilização, em sua grande maioria, não está sendo acompanhada de um processo amplo de discussão dos aspectos teóricos e práticos envolvidos. Cabe ressaltar, que a utilização das TIC, dentre elas a Internet em especial, vêm se apresentando como ferramenta bastante acionada para a construção do conhecimento (LEÃO, 2011). Devemos enfatizar que as tecnologias são instrumentos de mediação deste processo, não podendo ser considerado, portanto, como ator principal na construção do conhecimento por parte do aprendiz (LEITE, LEÃO e ANDRADE, 2010) ou como substituto de outros recursos (LEITE, 2014). Ademais, é fundamental uma maior adequação da escola, dos professores e dos alunos para um adequado uso da internet neste contexto. Cysneiro (2011) discute sobre as competências necessárias para o professor atuar como mediador do processo de ensino e aprendizagem dentro da sociedade da informação e Carvalho (2012) defende o uso dos recursos didáticos digitais no ensino. Outros autores (LEÃO, 2011; CARVALHO, 2012; MATAR, 2013; PORTO e SANTOS, 2014; LEITE, 2015) destacam as vantagens e desvantagens do uso das tecnologias no ensino, além de um novo olhar sobre a formação inicial continuada de professores para o uso das tecnologias no ensino (MATTAR, 2013; LEITE, 2015).

Nesse sentido, buscando contribuir para um melhor uso das TIC no processo de ensino e aprendizagem, em especial no que diz respeito à Internet e seus recursos Web 2.0, propomos a incorporação da Teoria da Flexibilidade Cognitiva (TFC) de Rand Spiro (1990) e a Teoria dos Construtos Pessoais (TCP) de George Kelly (1963) na elaboração dos materiais Web 2.0. A TFC propõe a construção de uma aprendizagem flexível a partir do contato do aprendiz com o mesmo conhecimento em diversos contextos, bem como a relação deste conhecimento nestes vários contextos. A TCP se utiliza de um sistema de construtos, que nos permite prever e descrever os acontecimentos a partir de uma estrutura complexa de conceitos, além de analisar as escolhas 
livres, e como o processo de aprendizagem decorre a partir dessas escolhas. Acreditamos, dentro do contexto do uso de ferramentas Web 2.0, que uma articulação da TCP e da TFC poderá propiciar a construção de uma aprendizagem ampla e flexível.

Este trabalho teve como propósito analisar a utilização de alguns recursos da Web 2.0, e como estes estão sendo inseridos no Ensino das Ciências, em especial no Ensino de Química, a partir da incorporação da TFC e da TCP em ambientes Web 2.0. O campo de estudo da presente proposta se insere na área voltada para a utilização das tecnologias da informação e da comunicação no ensino de ciências, esperando com isto, contribuir para a formação de cidadãos capazes de se expressar utilizando a linguagem da Web 2.0, e de refletir sobre suas produções e de outros, procurando ainda perceber, as possibilidades e os limites no uso da Internet na Educação.

\section{Web 2.0}

Com a incorporação das Tecnologias da Informação e Comunicação a prática educativa, muito se tem discutido sobre as competências tecnológicas que os docentes deviam adquirir no processo de sua formação. A Web 2.0 (termo que faz relação com o tipo de notação em informática que indica a versão de um software) é a segunda geração de serviços online e se caracteriza por potencializar as formas de publicação, compartilhamento e organização de informações, além de ampliar os espaços para a interação entre os participantes do processo (O'REILLY, 2005; CORRÊA, 2012; LEITE, 2015).

A Web 2.0 se refere não apenas a uma combinação de técnicas informáticas, mas também a um determinado período tecnológico, a um conjunto de novas estratégias mercadológicas e a processos de comunicação mediados pelo computador. A mesma tem repercussões sociais importantes, que potencializam processos de trabalho coletivo, de troca afetiva, de produção e veiculação de informações, na (re)construção do conhecimento apoiada pelos recursos tecnológicos. Um dos princípios fundamentais que abarca a Web 2.0 é trabalhar a própria Web como uma plataforma, isto é, viabilizando funções on-line que antes só poderiam ser conduzidas por programas instalados em um computador. Além de novas ou potencializadas formas de publicação e circulação de informações, a Web 2.0 potencializa a livre criação e organização distribuída de informações compartilhadas através de associações mentais. Considerando tais premissas, defende-se que o estudo da Web 2.0 deve levar em conta não apenas os aspectos tecnológico e de conteúdo, mas também as interações sociais quanto a sua forma: o aspecto relacional (BATESON, 1980; FISHER, 1987; ROGERS, 1998; MOREIRA e DIAS, 2009).

Com a introdução da Web 2.0 as pessoas passaram a produzir os seus próprios documentos e a publicá-los automaticamente na rede, sem a necessidade de grandes conhecimentos de programação e de ambientes sofisticados de informática. Os softwares da Web 
2.0 geralmente criam comunidades de pessoas interessadas em um determinado assunto, a atualização da informação é feita colaborativamente e torna-se mais confiável com o número de pessoas que acessam e atualizam (ALEXANDER, 2006; OLIVEIRA e DUTRA, 2014; KAY e ANDRADE, 2014). Recentemente temos presenciado uma ampla expansão do conceito da Web 2.0, cuja principal característica poderia ser a substituição do conceito de uma web de leitura, para uma de leitura-escrita. O estudo da Web 2.0 deve levar em conta não apenas os aspectos tecnológicos e de conteúdo, mas também as interações sociais envolvidas no aspecto relacional. Diariamente centenas de novas páginas são construídas com os ideais que definem a Web 2.0. Algumas diferenças entre a Web 1.0 e a Web 2.0 são descritas a seguir. .

-Web 1.0: Utilizador é consumidor da informação; Dificuldades inerentes a programação e a aquisição de software específico para criação de páginas na web; Para ter um espaço na rede na maioria dos servidores é preciso pagar; Menor número de ferramentas e possibilidades.

-Web 2.0: O utilizador é consumidor e produtor da informação (prosumidor); Facilidades de criação e edição de páginas online; $O$ utilizador tem vários servidores para disponibilizar suas páginas de forma gratuita; Número de ferramentas e possibilidades ilimitadas.

Devemos entender que a Web 2.0 não é definida como sites de jogos ou ferramentas da Internet, nem tampouco um website específico de pesquisas na Internet. A Web 2.0 não é uma nova web com novas linguagens ou tecnologias, alguns dos recursos mais notáveis da Web 2.0, como blogs ou wikis, vêm do nineties. Mas algumas tecnologias são a chave do desenvolvimento de sites da Web 2.0, como o Ajax ou Mash-ups. Quando a mudança da Teia Mundial (www) foi notada, algumas diferenças entre os novos sites e os antigos são percebidas, promovendo criatividade e compartilhamento de informação. Encontramos tecnologias específicas como wikis e blogs, com novos caminhos para criação de webpáginas como mashups, e uso massivo de descritores ou tags (marcadores) que tem sido definido como folksonomies. Taxonomia vem do grego "taxis" e "nomos": Taxis significa classificação, nomos (ou nomia), ordenar, negociar; por sua vez, "folc" provém do alemão "pueblo" (Volks). Logo etimologicamente, folksonomies (ou folcsonomía - folc + taxo + nomía) significa "classificação gerenciada por um povo".

Cobo e Pardo (2007) foram os primeiros a ordenar a Web 2.0 em quatro linhas fundamentais: Social Networking (Redes sociais) que descreve todas as ferramentas desenhadas para a criação de espaços que promovam ou facilitem a construção de comunidades de intercâmbios sociais; Conteúdos que fazem referência as ferramentas que favorecem a leitura e a escrita online, assim como sua distribuição e intercâmbio; Organização Social e inteligência da informação as ferramentas e recursos para marcar, organizar e indexar, facilitando a ordem e armazenamento da informação, assim como de outros recursos disponíveis na rede; Aplicações e serviços (Mashups) esta classificação inclui inúmeras ferramentas, softwares, plataformas online e diversos recursos criados para oferecer serviços ao usuário. 


\section{Ferramentas da Web 2.0}

Um aspecto positivo das ferramentas da Web 2.0 é a aquisição de programas gratuitos (freeware) o que facilita a produção dos materiais na Web 2.0. O uso fácil e gratuito destes novos serviços web é a chave para entender a evolução da Internet para a Web 2.0 (DE CLERCQ, 2009, SANTOS e CYPRIANO, 2011; LIMA, 2014). Dentre inúmeras ferramentas que a Web 2.0 disponibiliza, descrevemos a seguir o blog e as Redes sociais.

O termo "weblog" foi primeiramente usado por Jorn Barger, em 1997, para referir-se a um conjunto de sites que "colecionavam" e divulgavam links interessantes na web. Os blogs são ferramentas para "escrever" e para "ler". São recursos para difundir e compartilhar conteúdos por expertos, analistas, especialistas, docentes, alunos, grupos afins, classes sociais, escolas, adultos e jovens. No blog os professores podem produzir ambientes de aprendizagem dinâmico sem o conhecimento prévio de uma linguagem informática (ex. HTML). O blog é provavelmente a ferramenta da Web 2.0 mais conhecida e utilizada em contexto educativo. O usuário pode contribuir com seus comentários, votar, etiquetar, recomendar ou reprovar qualquer conteúdo da web (ALIER, 2009; OLIVEIRA e DUTRA, 2014; KAY e ANDRADE, 2014).

As aplicações pedagógicas de blogs são inúmeras, por exemplo, antes os alunos utilizavam o caderno, hoje fazem uso da digitalização da escrita, até para atividades que provoquem o aluno a criar, escrever textos, fazer produções dos mais diversos formatos. O blog pode quebrar a hierarquia que existe na sala de aula. A pessoa pode se dirigir ao professor sem muito protocolo e vice-versa. Outro importante ponto é a necessidade de atualização constante dos conteúdos para despertar o interesse dos alunos, isso faz com que o blog fique movimentado. É importante destacar que os blogs não foram criados no contexto educacional. Não tinham esse objetivo. Eles inicialmente eram relatórios publicados na internet e começaram a ser usados para diferentes fins por conta da facilidade de uso, daí a característica de sua interatividade. Comparado a um site convencional, os blogs apresentam um processo de construção e escrita muito mais rápido, além da possibilidade da publicação ser instantânea.

As ideias mais relevantes nos processos de aprendizagem com o suporte dos blogs são inúmeras, desde possibilidades em torno do desenvolvimento de habilidades de trabalho colaborativo à construção do discurso necessário para o desenvolvimento intelectual e nos processos de interiorização de conceitos, a capacidade de expressão, contribuição de ideias e conteúdos. Com os blogs podemos também investigar, indagar, discutir os pontos de vista, baixar informações segundo conhecimentos, fontes, recursos e interesses.

Alguns professores têm uma dificuldade em utilizar o blog. Ainda existe uma grande resistência. Não veem o blog como uma possibilidade de ampliação, como quebra das barreiras em sala de aula. Porém, às vezes, essa repulsa por blogs é na verdade consequência da falta de 
intimidade dos professores com o computador. Existe ainda hoje professor sem e-mail, entretanto, um problema encontrado na utilização dos blogs é a falta de tempo disponível dos professores para atualizar. O blog perde a dinamicidade, por isso é importante organizar-se em metas de atualização para manter o blog dinâmico. A disciplina e os hábitos do trabalho constante que implica em manter um blog, planificar, acrescentar uma nova informação periodicamente, consultar cada dia fontes de informação nas áreas de interesse, estar flexível e escrever cotidianamente. A motivação, o reconhecimento e o auto reconhecimento no caminho criativo são importantes para manter um blog.

No que diz respeito as Redes Sociais, chamamos Sociedades conectadas a um sistema reticular, tecido e composto por indivíduos e organizações que é susceptível de relacionar conjunturalmente aos distintos acontecimentos sociais (MARTIN, 2009). A "Internet social" é uma série de aplicações e páginas de Internet que utilizam inteligência coletiva para proporcionar serviços interativos em rede cedendo ao usuário o controle de seus dados e dando uma capacidade ativa, produtora. A recente expansão e crescimento dos sítios de redes sociais na Internet como Google+, Facebook, Twitter, Myspace, Craigslist, Bebo entre muitos outros, estão despertando o interesse dos acadêmicos (LIVINGNSTONE, 2009; PORTO e SANTOS, 2014; OLIVEIRA e DUTRA, 2014; KAY e ANDRADE, 2014; LIMA, 2014). As redes sociais permitem uma comunicação entre círculos expansivos de contatos, e uma convergência entre, até agora separadas, ações como o correio eletrônico, a mensagem instantânea, a criação de webs, os diários, os álbuns de fotos, e a baixar e enviar músicas e vídeos. As Redes Sociais são espaços virtuais onde as pessoas se encontram e formam redes de relacionamento. A rede social College.com é um exemplo de rede social voltada para os estudantes universitários.

Os processos de comunicação na Web são, cada vez mais, sistemas de relacionamento entre iguais que geram novas formas de construção do conhecimento, mais sociais e mais dependentes da comunidade. E ao mesmo tempo, a capacidade individual de autogestão da própria aprendizagem é mais importante para poder aproveitar esses sistemas de conexões, redes de pessoais e recursos.

As pessoas que se conectam online por um período prolongado podem, mas não necessariamente vão, gerar uma comunidade virtual, é preciso convencer outras pessoas a manter essa comunicação. Para atraí-las é preciso ter um meio que esteja nos interesses em comum. É importante ainda enfatizar que é preciso a presença de alguns elementos chamados elementos formadores, que seriam as discussões públicas, as pessoas que mantém contato via Internet, que se encontram e reencontram tempo e sentimento. Esses elementos constituem uma comunidade virtual. Além dos elementos formadores, podemos afirmar, que as comunidades virtuais possuem algumas características, dentre elas: Interatividade no que diz respeito às trocas comunicativas. De acordo com Primo (2007), é preciso partir da interação humana para compreender a interatividade na comunicação humano-computador. $O$ autor propõe dois 
conceitos, o de interação mútua e interação reativa. A primeira acontece de forma aberta, onde a relação se dá através da construção negociada, e a segunda em um sistema fechado, a relação é causal e é baseada no objetivismo. Outra característica é a Permanência, na qual Recuero (2009) descreve que é imprescindível para manter ativas as comunidades virtuais, pois caso contrário não existe possibilidade de aprofundar as relações entre as pessoas, requisito sine qua non, para que uma comunidade se constitua.

Destacamos que nas comunidades virtuais é importante fazer com que os membros delas sintam que pertencem as mesmas, precisam internalizar o sentido de comunidade.

\section{Aprendizagem 2.0}

A educação tem sido uma das áreas mais beneficiadas com a "interferência" das novas tecnologias, especialmente as relacionadas com a Web 2.0. Por ela, resulta fundamentalmente conhecer e aproveitar a bateria de novos dispositivos digitais, que abrem inexploradas potencialidades a educação e a investigação. A Web 2.0 se trata de um território potencial de colaboração na qual podemos empregar de maneira adequada processo de ensino e aprendizagem. Um dos principais benefícios destas novas aplicações web - de uso livre e que simplificam tremendamente a cooperação entre pares - responde ao princípio de não requerer do usuário uma alfabetização tecnológica avançada. Estas ferramentas estimulam a experimentação, reflexão e a geração de conhecimentos individuais e coletivos, favorecendo a conformação de um ciberespaço de interatividade que contribui a criar um ambiente de aprendizagem colaborativo.

Segundo Johnson (2001) existe três tipologias diferentes de aprendizagem:

1. Aprender fazendo (Learning-by-doing): para esse tipo de aprendizagem as utilizações das ferramentas permitem ao estudante e/ou professor a leitura e a escrita na Web, baseados no princípio de "ensaio-erro". Este processo de criação individual e coletivo, por sua vez, promovem um processo de aprendizagem construtivista.

2. Aprender interatuando (learning-by-interacting): além da escrita oferecem a possibilidade de intercâmbio de ideias com os demais usuários da internet. A ênfase é aprender interatuando com os demais.

3. Aprender buscando (learning-by-searching): um dos exercícios de um trabalho, pesquisa ou outra atividade é a busca de fontes que ofereçam informação sobre o tema que se abordará. Esse processo de investigação, seleção e adaptação termina ampliando e enriquecendo o conhecimento de quem o realiza. 
Lundvall (2002) acrescenta a esta taxonomia um quarto tipo de aprendizagem, que representa o valor essencial das ferramentas Web 2.0 e que está baseado na ideia de compartilhar informações, conhecimentos e experiências:

4. Aprender compartilhando (learning-by-sharing): o processo de intercâmbio de conhecimentos e experiências permitem aos educandos participar ativamente de uma aprendizagem colaborativa. Ter acesso à informação, não significa aprender, por isso, a criação de instâncias que promovam compartilhar objetos de aprendizagem e enriqueçam significativamente o processo educativo.

Nesse contexto a Web 2.0 multiplica as possibilidades de aprender a compartilhar conteúdos, experiências e conhecimentos. Os recursos online da Web 2.0, além de serem ferramentas que aperfeiçoam a gestão da informação, se convertem em instrumentos que favorecem a conformação de redes de inovação e geração de conhecimentos baseados na reciprocidade e na cooperação. A partir deste marco (gerar e compartilhar) temos o modelo de Aprendizagem 2.0 (aprender fazendo, aprender interatuando, aprender buscando e aprender compartilhando). Cada um destes tipos de ensino e aprendizagem enriquece as plataformas Web 2.0 cujas características mais relevantes é oferecer ao professor aplicações uteis, gratuitas, colaborativas e simples de usar.

\section{Teoria dos Construtos Pessoais}

A construção do conhecimento, na perspectiva de George Kelly (1970), é baseada em uma teoria psicológica, que ele denominou Alternativismo Construtivo. Essa teoria, Teoria dos Construtos Pessoais (TCP), é composta de um postulado fundamental e onze corolários (Construção, individualidade, organização, dicotomia, escolha, faixa, experiência, modulação, fragmentação, comunalidade e sociabilidade). De acordo com essa teoria, as pessoas são livres para escolher como querem ver o mundo, e seu comportamento decorre dessas escolhas.

Elas são responsáveis por suas ideias e por suas mudanças. A aprendizagem, segundo a TCP, é resultado das tentativas da pessoa de lidar com suas experiências. Desse modo, o conhecimento é relativo, é construído pessoalmente, de acordo com as experiências, e também é possível mudá-lo por sucessiva experimentação. Além disso, a pessoa é quem toma as decisões, principal responsável por suas ideias e pela mudança nas mesmas. Ao construir o modelo do sistema antecipatório as pessoas tentam aperfeiçoar esse sistema de modo que lhes permitam compreender cada vez melhor o que vai acontecer se eles agirem de certa maneira. Nesse caso, a aprendizagem é considerada como o resultado de tentativas da pessoa em compreender a realidade e de lidar com eventos a partir de suas experiências (Corolário da experiência).

Uma página Web 2.0 pode ser observada seguindo o ciclo proposto por Kelly (1963) em que o prosumidor (produtor e consumidor da informação) ao acessar determinado recurso, 
antecipa de forma que analisa este recurso na busca de informações que são pertinentes a sua necessidade, em que outro prosumidor de recursos com uso da Web 2.0 investe nestes recursos disponibilizando informações, permitindo um encontro da necessidade de ambos prosumidores um em produzir e outro em consumir - chegando a uma avaliação do conteúdo disponibilizado na Web 2.0 se é ou não resposta da busca inicial.

\section{Teoria da Flexibilidade Cognitiva}

A mediação pedagógica pautada no uso das tecnologias disponíveis na Web 2.0 necessita de uma abordagem baseada em metodologias centradas nos alunos, com atividades que permitam a construção de conceitos complexos e pouco estruturados, em especial dentro do contexto do ensino de ciências. Neste sentido, uma teoria que se adéqua a este tipo de proposição é a Teoria da Flexibilidade Cognitiva (TFC).

A TFC foi proposta na década de 80, por Rand Spiro e colaboradores. É uma teoria de representação e instrução, com o objetivo principal de promover o conhecimento não de forma linear e apenas como memorização, porém, considerando que o aprendiz deve desenvolver a sua capacidade cognitiva, de forma a ser capaz de usar qualquer conhecimento em situações reais diversas, diferentes daquelas em que foi preparado durante sua formação. Por flexibilidade cognitiva se quer dizer a capacidade para reestruturar o conhecimento de alguém, de muitas maneiras, em uma resposta adaptável às exigências situacionais. O desenvolvimento da flexibilidade cognitiva requer múltiplas representações do conhecimento, que favoreçam a transferência desse saber para novas situações (SPIRO e JEHNG, 1990).

A Teoria dos Construtos Pessoais (TCP) de Kelly, bem como a Teoria da Flexibilidade Cognitiva (TFC) de Spiro e colaboradores, apresentam alguns pontos de articulação na elaboração de materiais Web 2.0. Levando em consideração uma teoria de aprendizagem que focasse os princípios norteadores da elaboração de materiais na Web 2.0, tomamos a TFC como sendo a teoria de suporte para atingir os objetivos do nosso trabalho. Tomando referência às análises da compreensão dos alunos-usuários quando exposto a complexidade da realidade em que vive, recorremos a TCP para traçar o perfil de sua visão e estabelecer possíveis articulações entre a TFC e a TCP.

\section{Metodologia}

O desenvolvimento desta investigação seguiu os moldes de uma pesquisa qualitativa. Segundo Lüdke e André (2012) uma pesquisa qualitativa tem o ambiente natural como sua fonte direta de dados e o pesquisador como seu principal instrumento; os dados coletados são 
predominantemente descritivos; o significado que as pessoas atribuem às coisas e à sua vida constituem-se em focos de atenção do pesquisador.

a) Universo da Investigação

Seis (06) turmas do $1^{\circ}$ ano do ensino médio, todas da rede privada de ensino, das quais quatro (04) utilizaram os recursos da Web 2.0 e duas (02) não a utilizaram como recurso no ensino de Química. O tema abordado para aplicação dos objetos de pesquisa foi Ligações Químicas em todas as turmas. Dividimos em Turma A1 (com 14 alunos), Turma A2 (21 alunos), Turma A3 (com 40 alunos) Turma B (23 alunos), Turma C1 (48 alunos) e Turma C2 (35 alunos). Os alunos estavam dentro de uma faixa etária de 14 a 16 anos.

b) Etapas da investigação

Pré-seleção (contato com os materiais a serem pesquisados): A parte inicial da pesquisa aconteceu na Internet, especificamente em sítios Web 2.0, através da escolha de webpáginas, comunidades, blogs e twitter's utilizados como recursos para o Ensino de Química. Essa pesquisa foi realizada utilizando-se mecanismos de busca: Google, Yahoo Search! e Bing. A utilização desses mecanismos foi devido a grande quantidade de dados disponibilizados por busca, permitindo uma análise ampla dos objetos de pesquisa. A Pré-seleção dos objetos de pesquisa (Webpáginas, comunidades, blogs e Twitters da Web 2.0) foi destinada a escolha de materiais relacionados com o ensino e aprendizagem. Nessa investigação foram considerados os materiais que apresentavam, dentro da interpretação do investigador, uma aprendizagem flexível e de escolha livre, com subsídio de aprendizagem 2.0.

Seleção: escolheu-se três objetos de pesquisa de cada área da Web 2.0 para análise (uma Webpágina, uma rede social e um blog).

Aplicação: foram aplicados dois questionários (inicial e final), constando perguntas sobre o conteúdo abordado, além de uma intervenção sobre utilização dos objetos de pesquisa selecionados.

Análise: Investigou-se o uso, os objetivos da página, os acessos, seus recursos e como contribuem para uma aprendizagem flexível. Dessa maneira os resultados poderão permitir estabelecer pressupostos para o uso da Web 2.0 no Ensino de Química, além de possibilitar a avaliação de estratégias de uso.

Conclusão: discussão após o término das atividades previstas, compreendendo várias tarefas como: consolidação de resultados, relatórios finais e atividades de avaliação.

Para as turmas que utilizaram os recursos Web 2.0 no ensino de Química (Turmas de A1, A2, A3 e B), foram seguidas as seguintes etapas: Questionário inicial, intervenção e questionário final. A turma B teve sua intervenção livre. As turmas C1 e C2 seguiram apenas as etapas: questionário inicial e final. 
A intervenção constou da aplicação de três ferramentas selecionadas para cada turma, nesta etapa se procurou não repetir as três ferramentas nas turmas. $\mathrm{Na}$ intervenção foram selecionados os seguintes instrumentos: Turma A1 utilizou a rede social Scribd (http://www.scribd.com/doc/3185893/Ligacao-Quimica), o blog Celeste Paula (http://celestepaula.wordpress.com) e um portal: Colégio Web (http://www.colegioweb.com.br/quimica/ligacoes-quimicas) com características web 2.0. A turma A2 utilizou o vídeo disponibilizado na rede (parte 1: http://www.youtube.com/watch?v=rRqbXuCB2BU\&feature=related $\quad-\quad$ parte 2 : http://www.youtube.com/watch?v=w5W7uiLp9F4\&feature=related), o blog Bruno's Chemistry parte 1 discutindo sobre as ligações químicas, ligação iônica, covalente e metálica, além de tratar da história e da teoria do octeto (http://quimicadobruno.blogspot.com/2010/07/ligacoesquimicas.html) e Parte 2, referindo-se a teoria dos orbitais moleculares e teoria da ligação de valência: (http://quimicadobruno.blogspot.com/2010/08/ligacoes-quimicas-parte-ii.html) e um portal: Wikipédia (http://pt.wikipedia.org/wiki/Ligação_química). Turma A3 utilizou a rede social: Scribd (http://www.scribd.com/doc/32409444/Ligacoes-Quimicas), o vídeo do youtube (http://www.youtube.com/watch?v=vjETqU7-1RY\&feature=player_embedded) e um portal: Colégio Web (http://www.colegioweb.com.br/quimica/ligacoes-quimicas). Para a turma B a intervenção foi diferenciada, o professor solicitou aos alunos pesquisarem na internet (pesquisa livre) sobre ligações químicas, solicitando que eles utilizassem recursos diferentes da Web 2.0 (redes sociais, portais, blogs etc.) e entregar ao professor os links das três ferramentas web 2.0 pesquisada. As turmas C1 e C2 não utilizaram os recursos da Web 2.0.

c) Instrumentos

O questionário inicial foi dividido em duas partes: Questionário de perfil e o questionário de conteúdo (pré-teste). O questionário de perfil consta de dezessete (17) perguntas objetivas e subjetivas. Este questionário verifica o nível de condição do usuário em relação ao uso da internet. No questionário inicial além do questionário de perfil, os alunos responderam ao questionário de conteúdo (pré-teste). O questionário consta de cinco (05) perguntas subjetivas. Este questionário verifica o nível de conhecimento do aluno em relação ao tema que será abordado pelo professor. Este questionário tinha o objetivo de saber em que nível o aluno estava em relação ao conteúdo de ligações químicas.

O questionário final foi dividido em duas partes: Questionário de Conteúdo (pós-teste) e Questionário da Web 2.0. Nele os alunos responderam ao questionário de conteúdo (pós-teste) com cinco (05) perguntas subjetivas sobre ligação química, neste questionário seu objetivo é verificar o nível de conhecimento do aluno após a utilização dos recursos da Web 2.0 no tema proposto das ligações químicas. O questionário da Web 2.0 teve como objetivo verificar a contribuição da Web 2.0 no Ensino de Química. Este questionário foi aplicado após a intervenção. 
Nele consta de três (03) perguntas subjetivas, exceto para as turmas C1 e C2 que não participaram da intervenção, contendo apenas uma pergunta subjetiva.

\section{Resultados e discussão}

Destacamos uma síntese das semelhanças e/ou diferenças entre algumas respostas em relação aos questionários aplicados. Ressaltamos, que as diferentes respostas analisadas podem ser avaliadas como benéficas, haja vista a possibilidade de se discutir sobre a diversidade das respostas para a mesma pergunta. Ao total somaram-se 181 alunos que participaram da pesquisa $(A 1=14 ; A 2=21 ; A 3=40 ; B=23 ; C 1=48 ; C 2=35)$, destes 98 alunos $(54,2 \%)$ utilizaram alguma das ferramentas da Web 2.0 e 83 alunos $(45,8 \%)$ responderam apenas aos questionários.

\section{Em relação ao Questionário de Perfil}

No que se refere à pergunta sobre a utilização do computador ("Você usa computador?") dos 181 alunos que participaram do questionário, observando que todas as turmas participaram desta fase, $100 \%$ utilizam o computador, quer seja em casa $(86,2 \%)$, lan house $(10,5 \%)$ ou em outro ambiente $(3,3 \%)$. Cabe ressaltar que $2,2 \%$ dos alunos que utilizam o computador, fazem este uso na escola. Entretanto, é importante ressaltar, que apesar de todas as escolas que participaram desta pesquisa possuíam laboratório de informática com computadores com acesso à Internet, o percentual de apenas $2,2 \%$ que se utilizam desta ferramenta para fins educacionais é muito pequeno. Neste contexto observamos que em relação ao uso do computador na escola (“Com que frequência você usa o computador na escola?"), apenas $16,6 \%$, daqueles que o utilizam com fins educacionais o fazem mais de uma vez por semana.

Na discussão sobre a Internet ("Há quanto tempo você utiliza Internet?"), percebemos que $74 \%$ dos alunos acessam a Internet a mais de três anos e que deste grupo $77,9 \%$ acessam a rede mais de três vezes por semana ("Quantas vezes por semana você acessa a Internet?"). Esses dados repercutem na possibilidade do professor trabalhar com estes alunos atividades online (síncrona e/ou assíncrona), o que sem dúvida poderá tornar a aula mais atraente. A respeito da usabilidade da Internet (“O que você mais faz na Internet?"), observa-se uma forte utilização em processos interativos de comunicação, através dos chats, e-mails, fóruns etc., o que observamos no gráfico 1, a seguir: 


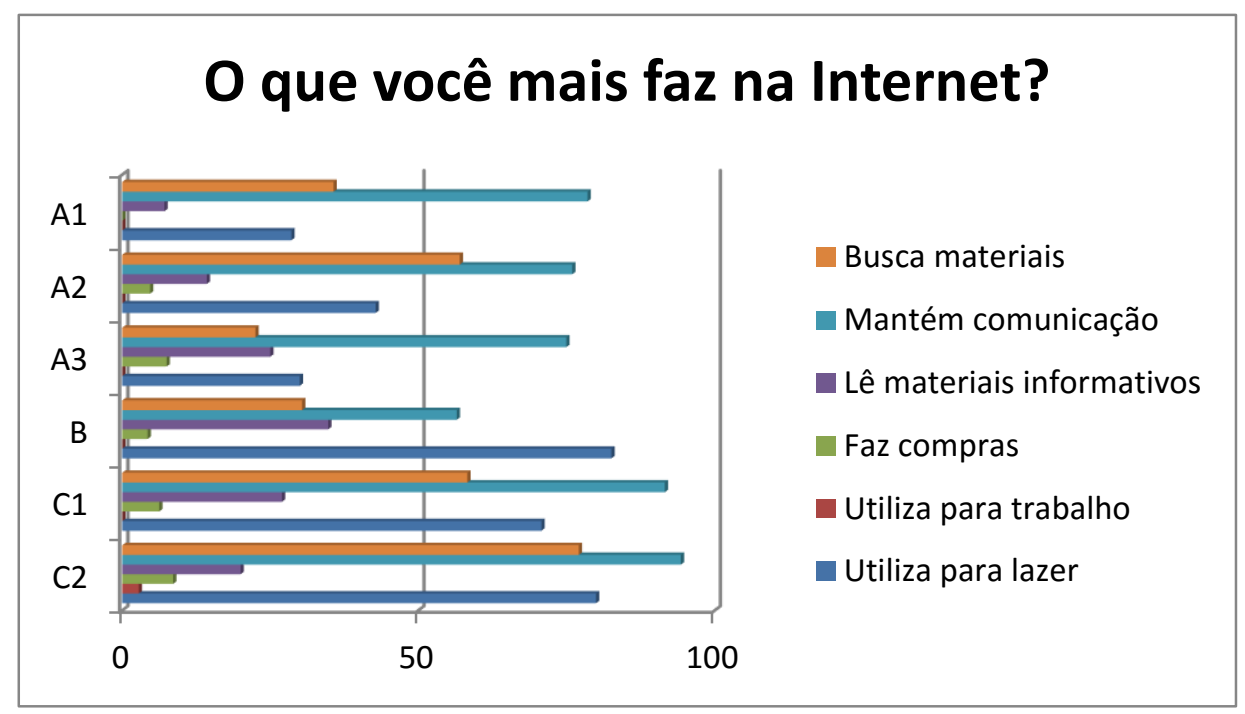

Gráfico 1 - Análise das turmas quanto ao uso da Internet.

Os dados apresentam uma grande semelhança entre as turmas investigadas, no aspecto de utilização de ferramentas da Internet para a comunicação entre as pessoas (superior a $75 \%$, exceto para a turma B). Este índice é reforçado quando analisamos o gráfico 2 que apresenta a "vantagem" da utilização da Internet como espaço para manter a comunicação.

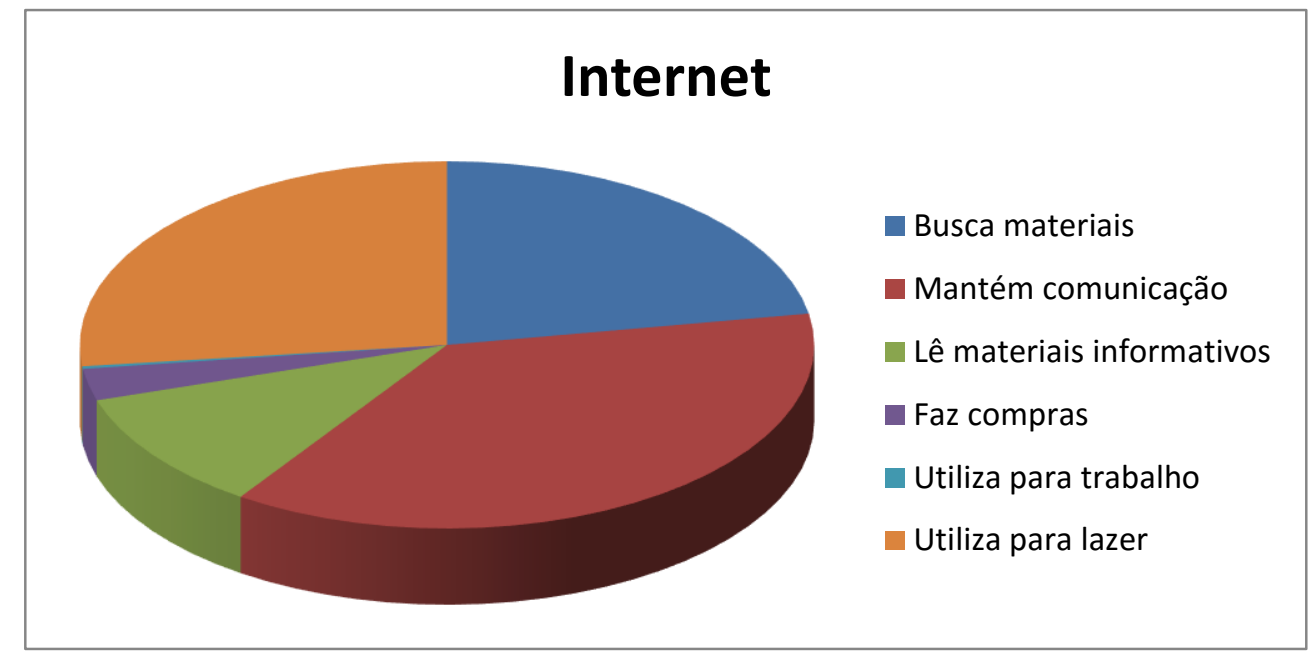

Gráfico 2 - Perfil geral da utilização da Internet pelos alunos.

Na pergunta "Qual recurso da Internet você mais utiliza?" observamos que os alunos têm uma alta frequência de acesso as redes sociais. Grossi e colaboradores (2014) evidenciam, por meio de uma análise multivariada, as preferências dos estudantes em utilizarem as Redes Sociais. Cabe ressaltar que a criação de redes sociais que valorizem o ensino pode ter uma grande contribuição para o processo de ensino e aprendizagem. Percebemos que além das redes sociais, os alunos utilizam também jogos online, o que abre perspectiva para a elaboração e utilização de jogos educativos, como uma boa estratégia. 0 gráfico 3 exibe as ferramentas mais utilizadas por estes alunos. 


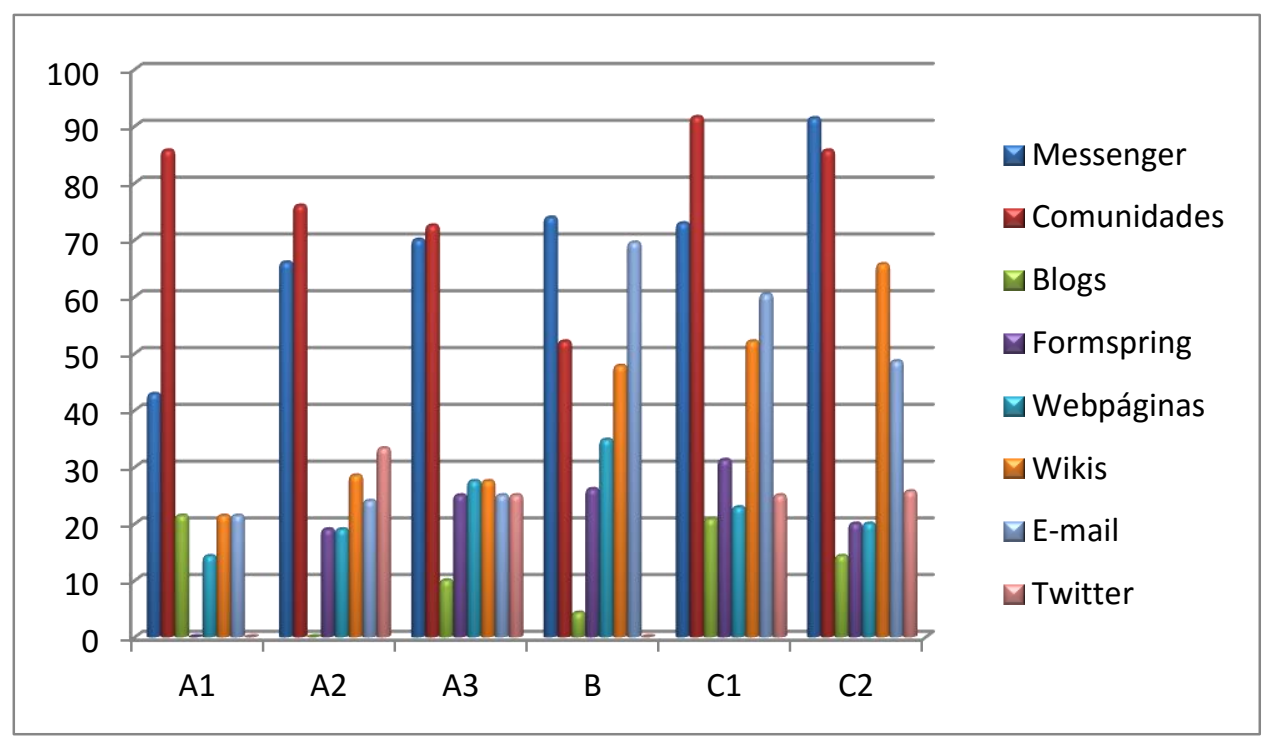

Gráfico 3 - Recursos mais utilizados.

Podemos observar (gráfico 4), que dentre as ferramentas, as mais utilizadas são as comunidades (79\%), o Messenger (72,4\%). A que apresentou o menor uso foram os blogs $(12,7 \%)$, o que deve estar relacionado à sua maior amplitude de informações e sua menor dinamicidade em relação as duas anteriores.

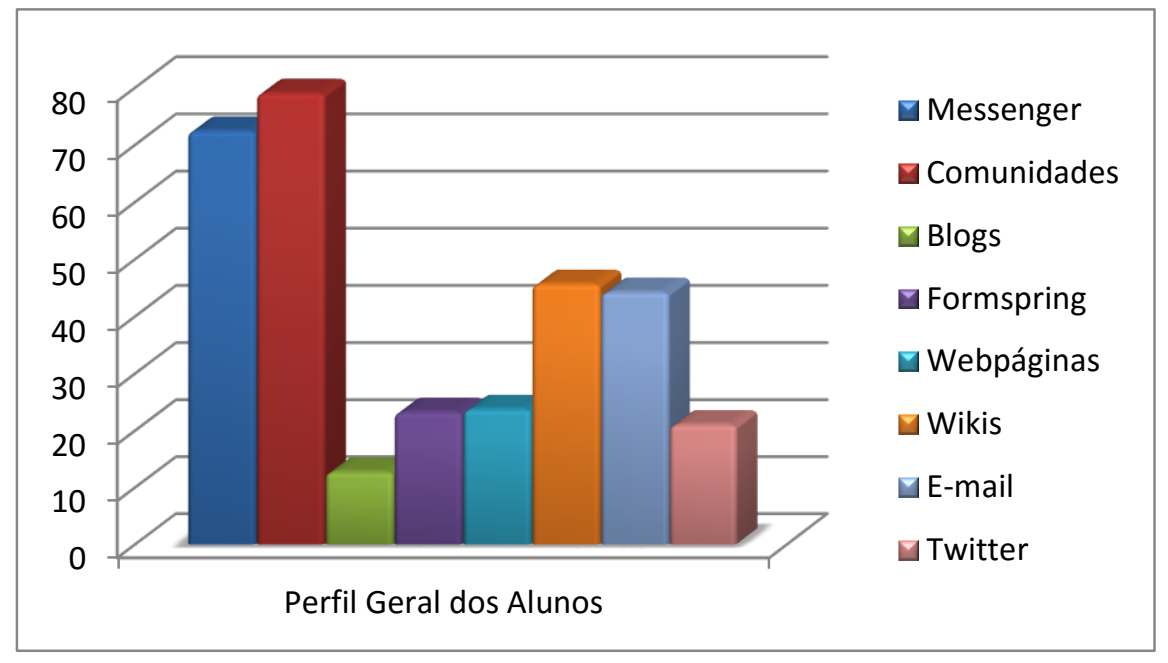

Gráfico 4 - Perfil geral dos recursos utilizados pelos alunos.

Da discussão sobre "Quais ferramentas de busca você já utilizou?", percebemos que a turma A3 não utiliza majoritariamente o mecanismo de busca do Google. Estes dados podem nos levar a conjecturar, que estes alunos, utilizam-se de outros mecanismos, em um processo de livre escolha mais acentuado, pois acreditam serem mais completos em relação aos que são comumente usados.

No que se discute sobre os conteúdos web ("Quanto à qualidade dos conteúdos que você encontra na Internet:"), dentre as turmas analisadas, uma das respostas chama a atenção devido ao fato de que o aluno, embora usuário da Internet, prefere confiar na qualidade dos conteúdos 
encontrados nos livros, através do uso da biblioteca da escola. Talvez este aluno, não confie na veracidade das informações fornecidas na Internet. Muito embora a rede disponha de diversas informações, nem sempre esses conteúdos são fidedignos. Este aluno deve optar pelo livro, por ser o material utilizado pelo professor, adotado pela escola, o que pode gerar mais confiança as informações obtidas. Entretanto, encontramos alguns sites de buscas recomendados para o meio acadêmico (LEITE, 2015). Esses mecanismos de busca nem sempre são bem conhecidos pelos professores e alunos, o que supostamente fez com que esse aluno prefira realizar suas pesquisas na biblioteca ao invés de utilizar a web.

Em relação a um tema pesquisado na Internet ("Quando você pesquisa um tema na Internet") grande parte dos alunos da turma A2, B e C2 ao encontrarem um material interessante param de ver as páginas o que não ocorre com as turmas A1, A3 e C1 em que a maioria dos alunos selecionam várias páginas para decidir depois o que vão utilizar. É interessante destacar que neste caso aqueles alunos (da turma A2, B e C2) não se preocuparam com a veracidade das informações o que pode acarretar no uso de informações incompletas ou incoerentes com o tema pesquisado. Nesse sentido, a escolha imediata do tema da pesquisa pode corroborar para uma aprendizagem errônea por parte daqueles alunos, de maneira que, ao encontrar o conteúdo eles não buscam outras fontes que confirmem as informações coletadas. Leite (2014) destaca a importância da pesquisa realizada na internet e enfatiza o papel do professor como mediador (CYSNEIRO, 2011) nesse processo. Os alunos tendem a ter hoje menores competências de leitura e de análise, optando na procura de informações "superficiais e sintéticas". Essa facilidade de encontrar conteúdos/informações pode ser prejudicial ao desenvolvimento de sua aprendizagem, quer na escola, quer no âmbito profissional.

Em relação a: "Na sua opinião: a) Que vantagens ou desvantagens existem na utilização de recursos da Internet durante as aulas das disciplinas que você estuda?"), observamos que as semelhanças citadas pelos alunos encontram-se na praticidade da aula, mais informações, por outro lado como desvantagem os alunos enfatizaram a distração durante a utilização das ferramentas da Web 2.0. Essas afirmações convergem com os relatos encontrados nas pesquisas com uso das tecnologias no ensino (LEÃO, 2011; MOREIRA e RAMOS, 2014; CARVALHO, 2012).

Uma outra observação extraída das respostas foi a de que os alunos acreditam que podem tanto aprender algo correto na Internet como aprender algo errado (Resposta de um aluno da turma A3: "vantagens de que você pode aprender algo, mais de desvantagens que nele você também pode aprender algo errado").

Os alunos também acreditam que com a utilização de ferramentas da Web 2.0 além da "aula ficar mais descontraída, ajuda-os a aprender melhor na maioria das vezes". Neste contexto, os jogos educativos foram considerados pelos alunos como a atividade mais proveitosa utilizando a Internet (“Na sua opinião: b) Que atividades (utilizando a Internet) podem ser mais proveitosas para a aprendizagem de um determinado conteúdo?"). Ainda, segundo os alunos que 
responderam ao questionário, a utilização da Internet em todas as disciplinas deve ser mais eficiente para sua aprendizagem. Nesse sentido, Ferreira e Bohadan (2014, p. 270) consideram que, o uso das ferramentas da Web 2.0 "oferece possibilidades bastante interessantes para a Educação" e "propõe também muitos desafios às práticas e concepções correntes, tanto de docentes quanto dos próprios alunos".

Por fim, na investigação sobre o conhecimento do aluno sobre a Web 2.0 ("Você sabe o que é Web 2.0? Dê exemplos"), apenas 9,39\% conhecia a Web 2.0. Um fato em comum para essas turmas é que 5,5\% acreditavam que a Web 2.0 se tratava de uma webcam nova. Neste sentido, é importante destacar que apesar da utilização da Web 2.0 por parte dos alunos ser grande, como notamos na utilização das redes sociais, os alunos não conseguem identificar as ferramentas da Web 2.0.

Este questionário empírico nos permitiu conhecer melhor o perfil dos alunos quanto a sua utilização da Web 2.0, e suscitou em nós diversas reflexões, que foram apresentadas nesta seção. Destacamos o alto acesso dos alunos a Internet em diversos locais e baixo na escola (embora essas escolas tenham laboratórios de informática disponíveis), o objetivo desses alunos ao acessarem a Internet, é em grande parte para comunicação. $O$ destaque das Redes Sociais no cotidiano dos alunos é notável, tendo o acesso praticamente diário da Internet, buscando continuamente estar em comunicação com outros usuários destas redes.

\section{Sobre o Questionário de Conteúdo}

No quesito "O que é uma Ligação Química para você? || Os átomos tendem a formar ligações, como você justificaria essas ligações?", percebemos que a utilização das ferramentas da Web 2.0 contribuiu para uma aprendizagem mais flexível e livre por parte dos alunos. Após as intervenções nas turmas (A1, A2, A3 e B), com ferramentas da Web 2.0, observamos que as respostas foram mais coerentes com o tema Ligação Químicas, além do aumento percentual que inicialmente era de $39,1 \%$ - 38 alunos de um total de 98 - para os que não sabiam o que era uma ligação química, e após a intervenção esse número caiu para 30,6\% (30 alunos) - gráfico 5. Em contrapartida, nas turmas que não utilizaram as ferramentas da Web 2.0 (sem intervenção - C1 e C2), esta diminuição passou de 44,6\% (37 alunos do total de 83) para 39,75\% (33 alunos). 


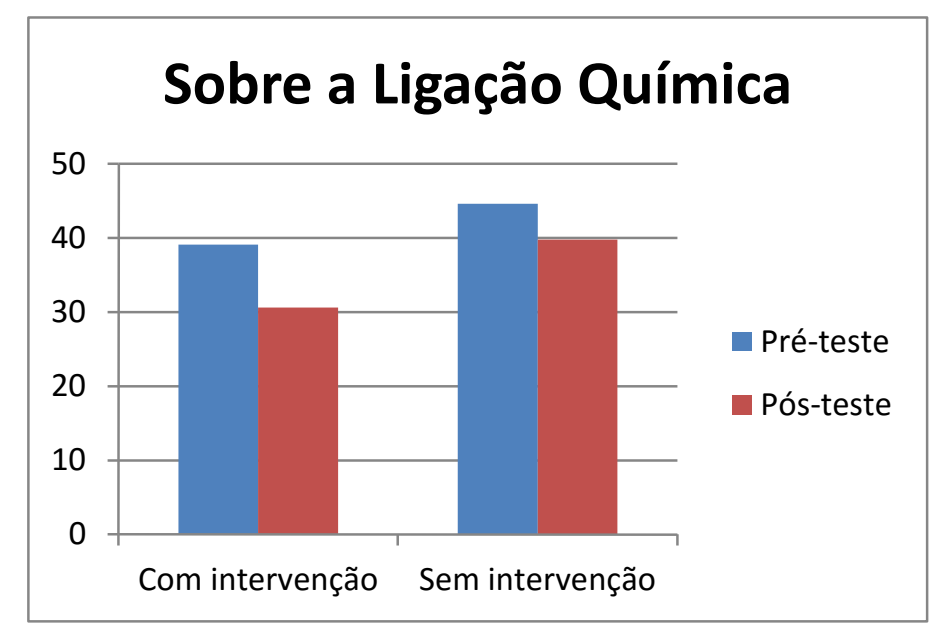

Gráfico 5 - Sobre as Ligações Químicas.

Sobre os tipos de ligações existentes ("Você sabe quais os tipos de ligações Químicas que existem? || Comente-as Como ocorre as ligações químicas? Explique cada uma"), percebemos que em relação as turmas que realizaram uma intervenção com ferramentas Web 2.0 o percentual dos que souberam responder aumentou consideravelmente (gráfico 6), passando de 39 alunos $(39,8 \%)$ no pré-teste para 71 alunos $(72,4 \%)$ no pós-teste. Entretanto, no que se refere as turmas sem intervenção, esta mudança foi de 8,4\% (7 alunos) para 32,5\% (27 alunos). Cabe ressaltar que embora as turmas (com e sem intervenção) tenham aumentado o seu percentual de respostas para o questionamento, é importante destacar que a utilização das ferramentas da Web 2.0 contribuiu de uma maneira mais significativa para as turmas que fizeram uso da intervenção.

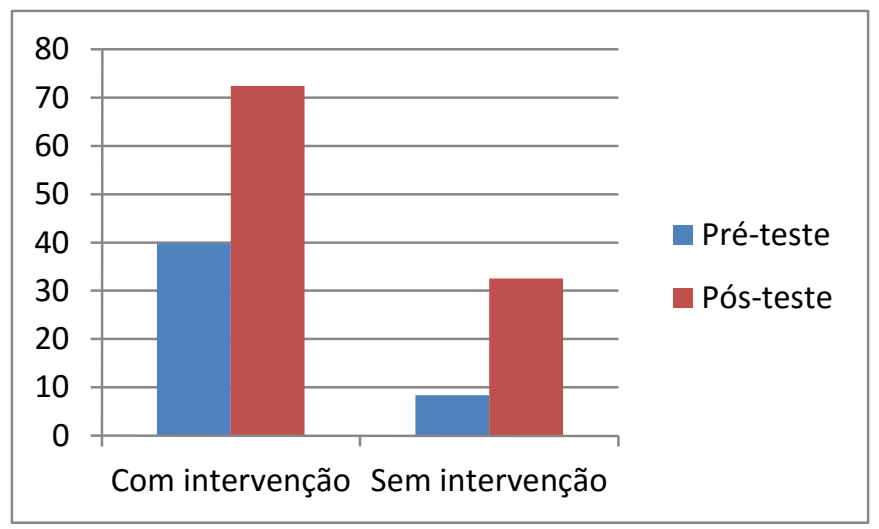

Gráfico 6 - Analise sobre os tipos de ligações.

No que diz respeito sobre a teoria do octeto no pré-teste ("Você já ouviu falar da regra do Octeto? Comente-as. II O que Lewis explicava sobre a regra do Octeto?"), observamos que poucos alunos tinham conhecimento desta teoria, entretanto, dois alunos da turma A3 descreveram a teoria do octeto de maneira distinta dos demais (Resposta do aluno: "Sim, foi a primeira tentativa de explicar como os átomos se ligam para formar substâncias químicas"), o que pode ser explicado pelo fato destes alunos terem no $9^{\circ}$ ano do ensino fundamental II, aulas iniciais de Química. Outro dado importante é que em todas as turmas (A1, A2, A3 e B) após a 
intervenção, observamos um aumento no número de respostas corretas para o questionamento (Gráfico 7).

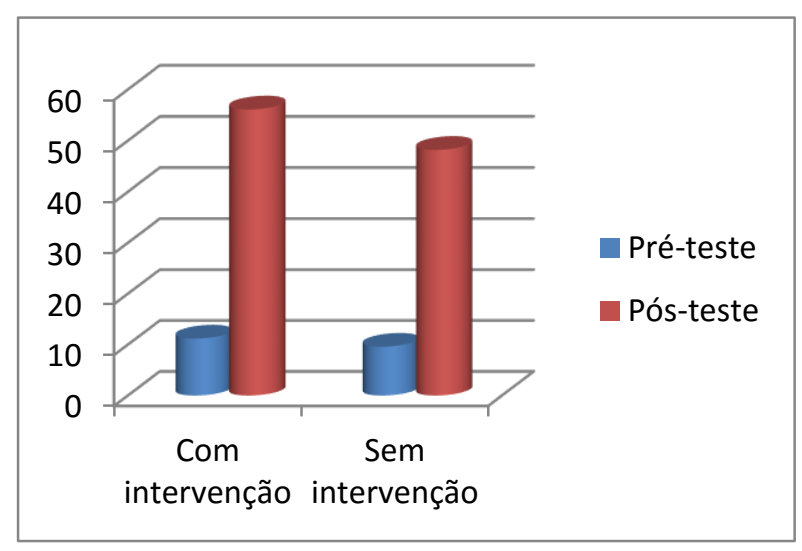

Gráfico 7 - Sobre a regra do Octeto.

A pergunta que envolve a Teoria da Ligações de Valência - TLV e a Teoria dos Orbitais Moleculares - TOM ("Você acha que existe alguma relação entre o conceito de ligação química e situações do seu cotidiano? Justifique || Sobre a teoria das ligações de valência e a teoria dos orbitais moleculares, quais semelhanças e diferenças existentes entre elas?"), envolveu um conteúdo que não é comumente discutido nas turmas do ensino médio. Nesse sentido, acreditamos que o pouco contato que tiveram com essas teorias, refletiu nas respostas a esta questão. 0 gráfico 8 apresenta estes dados.

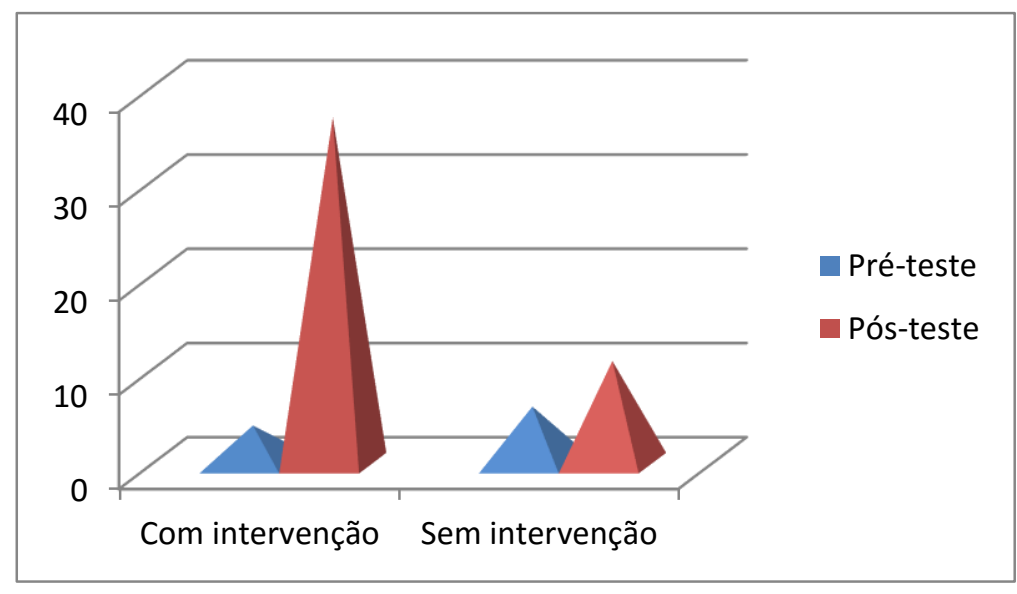

Gráfico 8 - Questionamento sobre a TLV e a TOM.

Mesmo assim, observou-se que os alunos das turmas que tiveram a intervenção, os resultados foram bastante consideráveis. Apenas 04 alunos responderam (no pré-teste) sobre as teorias, e após a fase da intervenção este número aumentou para 36 alunos. Observou-se ainda, que nas turmas que não trabalharam com nenhuma intervenção, esta mudança foi de 05 alunos no pré-teste para 09 alunos no pós-teste.

No último questionamento sobre as ligações químicas e o cotidiano dos alunos ("você acha que existe alguma relação entre o conceito de ligação química e situações do seu cotidiano? 
Justifique"), as respostas enfatizaram algumas características da Teoria da Flexibilidade Cognitiva. Estes alunos podem ter utilizado o conhecimento adquirido durante a utilização/visualização das ferramentas da Web 2.0, aplicando para diversas situações. A TFC é mais observada no pós-teste quando estes alunos são capazes de usar o conhecimento adquirido (antes do pós-teste) em situações reais diversas, diferentes das que foram preparados. Como a TFC busca estimular o aluno a desenvolver a sua capacidade cognitiva, o processo de aprendizagem nesta fase proporcionou a reflexão destes alunos (em relação ao tema das Ligações Químicas e o seu cotidiano) e possíveis conclusões durante a desestruturação deste conteúdo. A tabela 01 exibe o número de respostas envolvendo o questionamento realizado no questionário de conteúdo (préteste e pós-teste):

Tabela 1 - Respostas da relação entre o conceito de ligação química e situação do cotidiano.

\section{PRÉ-TESTE}

\begin{tabular}{ccc}
\hline Turma & $\begin{array}{c}\text { Sabiam de alguma relação entre } \\
\text { o conceito e seu cotidiano }\end{array}$ & $\begin{array}{c}\text { Não sabiam da existência de alguma relação } \\
\text { entre ligação química e seu dia-a-dia }\end{array}$ \\
\hline A1 & 04 & 10 \\
A2 & 05 & 16 \\
A3 & 23 & 17 \\
B & 14 & 09 \\
C1 & 16 & 32 \\
C2 & 17 & 18 \\
Total & 79 & 102 \\
\hline
\end{tabular}

PÓS-TESTE

\begin{tabular}{ccc}
\hline A1 & 10 & 04 \\
A2 & 07 & 14 \\
A3 & 28 & 12 \\
B & 20 & 03 \\
C1 & 36 & 12 \\
C2 & 19 & 19 \\
Total & 120 & 61 \\
\hline
\end{tabular}


No pré-teste $43,7 \%$ (79 alunos) sabiam que existia alguma relação entre ligação química e o seu cotidiano, enquanto no pós-teste 66,3\% (120 alunos) sabiam dessa relação. Observamos que em todas as turmas houve um acréscimo das respostas no que se trata do conhecimento de alguma relação do conceito de ligação química e o cotidiano destes alunos.

Algumas respostas dos alunos são mencionadas a seguir:

- "Acontecem muitas reações químicas em nosso dia-a-dia";

- "Nos produtos químicos que usamos";

- "A nossa vida e atividade que fazemos precisa de energia e isso envolve um processo químico";

- "Tudo que altera a estrutura da matéria é um fenômeno químico";

- "Se praticamente tudo ocorre via reações químicas e para elas ocorrerem tem que ocorrer algum tipo de ligação";

- "Sal de cozinha, a digestão, gás de cozinha, no corpo humano";

- "Sim. Pois assim como os elementos as letras também fazem ligações, algumas mais simples, formando palavras e outras mais complexas, formando frases";

- "Através dela que fazemos alguns materiais como peças para computador";

- "Gestos simples que são feitos no nosso cotidiano é uma demonstração de ligação química, que muitas vezes fazemos sem perceber";

- "Vários objetos são feitos através de uma ligação química, como exemplo: joias, carro, computadores, a junção dos metais semi-metais, forma esses objetos".

Alguns aspectos emocionais, outros sociais, e alguns científicos são apresentados nessas respostas, contudo a TFC pode estar inserida nas elucidações dos alunos.

Percebemos, que após a intervenção utilizando-se das ferramentas da Web 2.0, os alunos conseguiram responder de maneira mais coerente. Em comparação, nas turmas C1 e C2 que não utilizaram as ferramentas da Web 2.0, observamos um menor crescimento nas respostas coerente, o que nos permite inferir alguma contribuição das ferramentas da Web 2.0 no processo de ensino e aprendizagem por parte desses alunos. Acreditamos, que estas ferramentas contribuam para uma aprendizagem flexível e livre, levando em consideração que estes alunos ao acessarem a web podem escolher livremente os conteúdos dos quais utilizam para sua aprendizagem escolar. 


\section{Das sugestões sobre a Web 2.0 no Ensino de Química}

Sobre a contribuição da Web 2.0 ("Que contribuição os recursos da Web 2.0 teve ao assunto visto na sala de aula pelo professor?"), 93,8\% dos alunos (92 alunos do total de 98) enfatizaram que os recursos utilizados contribuíram para sua aprendizagem na sala de aula. Ademais, percebemos alguns corolários que podem ser associados com as respostas e quem tem base na TCP:

- Corolário da individualidade: em que as respostas se diferenciam uma das outras; Observamos por exemplo, nas respostas destes alunos "a facilidade de entender o assunto" ou "onde poderíamos nos divertir, podemos também aprender" e "não precisamos nos prender a apostila".

- Corolário da sociabilidade: à medida que algumas respostas dos alunos constroem a de outros, eles desenvolvem um papel social em relação ao outro; Nas respostas de um destes alunos encontramos a explicação de que "é importante para nós vermos a opinião de outras pessoas sobre o assunto". Nesse sentido o aluno constrói sua aprendizagem, com as contribuições de outros estudantes. Já para outro aluno, em suas palavras "Ajuda na busca do conteúdo, onde podemos tirar dúvidas com outras pessoas, procurando explicações que facilitam o entendimento do assunto". Nesta afirmação "Eu pude achar nele alguns portais que me ajudaram a entender minhas dúvidas" este aluno considera as contribuições de outrem para sua aprendizagem, também evidenciada nesta resposta: "Contribuiu muito pois na internet conseguimos ver mais coisas fora o que tem no livro. Como exemplo curiosidade de pessoas "perguntas" feitas no site e o bom é que a gente se baseia".

- Corolário da experiência: neste corolário o aluno constrói um sistema que varia a medida que se depara com outras situações; Conforme um dos alunos relata: "com as pesquisas feitas para ajudar em sala de aula, no que vimos na internet". Acreditamos que este aluno se refere às informações extraídas da internet, no sentido de contribuir para sua aprendizagem em sala de aula. Outro aluno relata que "com os sites indicados, tive acesso a mais conteúdo e 'pude' entender melhor o assunto". $\mathrm{O}$ acesso deste aluno a outras páginas contribuiu para que diante de explicações diversas alcançassem uma aprendizagem mais flexível.

- Corolário da escolha: na qual o aluno escolhe uma opção que é construída por eventos dicotomizados, em que antecipa uma maior possibilidade de extensão e definição do seu sistema de construção; Esses alunos afirmam que "sempre é bom acessar alguns sites e conhecer mais o assunto dado" e que as contribuições são "várias, pois com a ajuda de vários sites podemos encontrar textos, explicações e etc". Um dos alunos relata que "o fato de podermos ver exemplos melhores. Pelo recurso da imagem ajuda bastante", portanto a diversidade de informações que têm ao seu alcance esses alunos têm a possibilidade de escolher melhor tais recursos para contribuírem na sua aprendizagem. 
- Corolário da construção: esses alunos podem ter antecipado alguns eventos construindo suas réplicas. Um destes alunos considera que "é de extrema importância para que possamos desenvolver tudo que estudamos na sala de aula e na internet observamos tudo resumidamente com exemplos diferentes". Na perspectiva de outro aluno, "a busca foi importante não só para o trabalho, mas como um acréscimo de conteúdo".

- Corolário de faixa: um construto é conveniente para a antecipação de apenas uma faixa finita de eventos. Em uma das respostas, um dos alunos afirma que "Você fica com a ideia de como vai ser a aula, já com a revisão na mente, isso também auxilia na prova como 'revisão'.".

É importante ressaltar que no que diz respeito ao questionamento "Qual sua opinião sobre o uso da Web 2.0 para uma aula de Química?", 90,8\% das respostas (89 alunos das turmas A1, A2 A3 e B, de um total de 98 alunos) são favoráveis a utilização dos recursos da Web 2.0, o que possibilita ao professor (prosumidor) elaborar seu próprio recurso, para sua prática docente e que possivelmente a aceitação por parte dos alunos será significativa.

Por fim no que se refere a sugerir atividades com o uso da Web 2.0 ("Sugira alguma atividade com Web 2.0 que ajude no ensino de Química"), as turmas que utilizaram algum tipo de intervenção, 75,5\% (74 alunos) trouxeram sugestões para a aplicação da Web 2.0 no ensino, dentre as quais destacamos: testes online, criação de blogs (um dos alunos opina: "A sala pode montar um blog com assuntos de estudo em geral onde uma pessoa dá o tema e fala sobre ele e em seguida os outros comentam "dão" a sua opinião, fazem perguntas"), fichas de exercícios, no relato de um destes alunos sua sugestão está relacionada ao fato dele utilizar no seu trabalho (atividade proposta para a turma B) uma ficha de exercícios que encontrou em uma rede social, criação de comunidades, vídeos online sobre os conteúdos de química. Por outro lado, os alunos das turmas sem a intervenção, 71,1\% (59 alunos) comentaram como atividades possíveis, criar um laboratório virtual, criar blogs, fazer provas online, atividades online, para um dos alunos deve ser "com intuito de pontuar os alunos", já outro acredita que essas atividades sejam de "Alguma tarefa interativa que nos faça "correr" para "ganhar", como um gincana mesmo, pode fazer isso organizado no blog ou twitter", utilizar o Youtube (segundo estes alunos "por meio do vídeo podemos estudar química" ou "os vídeos explicam tudo"), sites com "Pesquisas sobre a matéria e atividades extra sala" ou "como páginas temáticas com os assuntos que estão ou irão estar sendo estudados" além do "compartilhamento de informações através da internet, mantendo contato através de sites aprimorando os estudos de uma forma diferente e acredito que divertida". Os alunos das turmas A1, A2, A3, e B expuseram mais respostas com o "perfil" da Web 2.0 (criação de objetos virtuais / uso de blogs / Criação de comunidades para ajudar no Ensino de Química). As turmas C1 e C2 apresentaram comentários e sugestões para a Web 2.0 no ensino (Utilização de enciclopédias online [Wikipédia] / utilização do Google e Youtube). 
Partindo da premissa dos dados analisados, as ferramentas da Web 2.0 utilizadas pelos alunos das turmas (A1, A2, A3 e B) provocaram alterações em sua rotina no que diz respeito a relações sociais, familiares, amorosas, trabalho, lazer, acesso à informação, aos meios de comunicação e principalmente no entendimento da Web 2.0 como ferramenta de aprendizagem.

\section{Considerações Finais}

Neste trabalho apresentamos uma experiência pedagógica em que um grupo de alunos de escolas diferentes trabalharam com algumas ferramentas da Web 2.0 durante um período no âmbito de uma disciplina de Química, envolvendo a temática: ligações químicas. Pensamos que os resultados obtidos, em especial as respostas livres em que os alunos equacionam o potencial educativo destas ferramentas, merece especial destaque.

Esperamos que a incorporação da Web 2.0 possibilite que professores e alunos se concentrem mais nos processos importantes de aprendizagem - que consistem na interpretação e organização da informação - que na mera transmissão de dados. Para que as Tecnologias da Informação e Comunicação, em especial as ferramentas Web 2.0, não seja vista como apenas mais um modismo, mas com a relevância e o poder educacional transformador que possuem, é preciso que se reflita sobre o processo de ensino e aprendizagem da sua aplicação em sala de aula.

Em síntese, observamos que os alunos destacaram o potencial educativo das ferramentas Web 2.0, bem como a importância da incorporação de atributos presentes na TFC e na TCP, em ambientes Web 2.0. Desta forma, esperamos que investigações nesta área possam contribuir de forma efetiva na utilização da Web 2.0 no ensino de ciências, considerando:

- Uma maior interação dos usuários da rede;

- Uma autonomia dos alunos nos fóruns de discussão existentes em diversas ferramentas da Web 2.0;

- Um despertar dos alunos e professores pelo interesse pela pesquisa na Web;

- Um uso efetivo e interdisciplinar do computador nas atividades de pesquisa;

- Um incentivo as publicações de textos, hipertextos e mídias educacionais construídos por parte dos alunos e dos professores;

- Um incentivo na elaboração de blogs, webpáginas, entre outros materiais educacionais embasados na Web 2.0.

Um dado importante, no que diz respeito aos jogos online, citados por diversos alunos, deve merecer especial atenção dos educadores. Os jovens jogadores desenvolvem novas habilidades e raciocínios, considerados valiosos em determinados tipos de ações profissionais. 
Neste contexto, o aluno deve aprender a selecionar informações para sua aprendizagem, ou seja, criar a necessidade de engajar-se de modo diferenciado na busca pela informação que seja compatível com o assunto estudado ou o problema a ser solucionado. Os graus de flexibilidade de ambientes para a aprendizagem estão claramente coadunados com a aceleração da temporalidade social, estabelecidas pelas inovações científicas e técnicas. No que concerne ao uso dos recursos da Web 2.0 na área de ensino traz consigo um desafio ainda maior, que é desenvolver também a competência de transformar a informação em saber construído.

No âmbito educativo, a Web 2.0 permite ao professor um ensino mais dinâmico, empolgante, atraente, entusiasmante. Assim, os alunos sentem a escola como um lugar em que se pode aprender de um modo inovador usando ferramentas atuais. As ferramentas da Web 2.0 permitiram uma melhor interação e cooperação com os alunos.

Em relação à educação, a Web 2.0 traz novas e diferenciadas possibilidades para que as pessoas possam se relacionar com os conhecimentos e aprender com outrem. Já não se trata apenas de um recurso a ser incorporado à sala de aula, mas de uma verdadeira transformação, que transcende até mesmo os espaços físicos em que ocorre a aprendizagem.

Podemos inferir que estes alunos/usuários fazem uso de ferramentas da Web 2.0 para aprender (aprendizagem 2.0); entretanto, é importante destacar que eles têm interesse em aprender o que atrai sua atenção (que nem sempre está focada em conteúdos escolares). Estes mesmos usuários procuram vídeos ensinando algo para a necessidade de seu dia-a-dia (conserto de computador, instalação de softwares, vídeos de como fazer, dúvidas sobre jogos). Por outro lado, alguns professores não conseguiram ainda incorporar essas ferramentas ao seu processo de ensino (SILVA, 2013; ROSA, 2013; FERNANDES, et al., 2013; ATAÍDE e MESQUITA, 2014; HOUGHTON, et al., 2015). O que pode ser por inúmeros motivos, tais como: falta de conhecimento técnico (embora as ferramentas da Web 2.0 não necessitam de conhecimentos específicos) e/ou pedagógico (cursos e capacitações em sua formação curricular que destaquem a importância da utilização de ferramentas com o uso da Web 2.0), resistência, medo, acomodação, falta de recursos na escola, falta de estímulo nas redes, falta de investimento, entre outros. Moreira e Januário (2014, p.79) enfatizam que "um dos desafios que se coloca ao professor é perceber como poderá utilizar pedagogicamente" essas ferramentas.

O futuro tecnológico da educação tem se direcionado para pequenas soluções na forma de aparelhos leves e portáteis, mas com muitos recursos para aprendizagem (celulares/Smartphones, notebooks, Ebooks, Leitores digitais/Tablets etc). Cabe ressaltar que por maior e melhor que seja a estrutura tecnológica, sozinha, ela não consegue realizar nenhum projeto de aprendizagem de qualidade, o investimento em capacitação de professores para o domínio técnico do uso de computadores também não resolverá os problemas envolvendo essas tecnologias. É preciso uma visão inovadora que contemple diversas perspectivas de 
aprendizagem, aproveitando-se das amplas possibilidades comunicativas e informativas das TIC para a concretização de um ensino crítico e transformador de qualidade.

O entendimento mais profundo dessas tecnologias no ensino, requer ainda estudos, mas a princípio já revela a importância da Web 2.0 como influência na vida individual e coletiva das pessoas, bem como na necessidade de transcender a persistente compreensão das TIC como ferramentas para a execução de atividades tradicionais. Muito embora as ferramentas da Web 2.0 sejam potencialmente capazes de prover um ambiente de ensino motivador, mais interativo, colaborativo e de comunicação rápida, ela tem sido usada de forma isolada por alguns educadores. Todavia, é certo que a atualização e a implementação da Web 2.0 estão incitando o surgimento de novas perspectivas de ensino e aprendizagem.

Destacamos que a apreensão dos alunos/professores de ferramentas da Web 2.0 (da tecnologia) vai além da incorporação de novas técnicas, de desenvolvimento de habilidades pelos alunos/professores, mas supera a reprodução, a transmissão de informações, pois pode permitir a potencialização de prosumidores criativos e solidários, mais humanos, ético e cidadão.

\section{Referências}

ALEXANDER, B. Web 2.0: a new wave of innovation for teaching and learning? Educase Review, v. 41, n. 2, p. 32-44, 2006.

ALIER, M. Nuevas maneras de compartir y distribuir los contenidos. In: GRANÉ, M., WILLEM, C. (Orgs.). Web 2.0: Nuevas formas de aprender e participar. Barcelona: Laertes Educacion, 2009, pp. 35-48.

ATAÍDE, J. F.; MESQUITA, N. A. S. O Arborescer das TIC na Educação: da raiz aos ramos mais recentes. Revista Brasileira de Ensino de Ciência e Tecnologia, v. 7, n. 1, p. 87-106, 2014.

BATESON, G. Mind and nature: a necessary unity. Nova lorque: Bantam New Age Books, 1980.

COBO, C. R.; PARDO, K. H. Planeta Web 2.0: Inteligencia colectiva o médios fast food. Grup de Recerca d'Interaccions Digitals, Universitat de Vic. Flacso México. Barcelona / México DF, 2007.

CARVALHO, A. A. Aprender na era digital: jogos e mobile learning. Santo Tirso: De Fact, 2012.

CORRÊA, E. C. D. Os artigos científicos em tempos de web 2.0: uma reflexão teórica. Revista ACB, v. 17, n. 1 , p. $42-58,2012$

CYSNEIRO, P. G. Professores e tecnologias da informação e comunicação: competências para ensinar nesta nova realidade. In: LEÃO, M. B. C. (Org.). Tecnologias na Educação: uma abordagem crítica para uma atualização prática. Recife: UFRPE, 2011, pp. 43-56.

312 DOI: Em andamento.

R. Bras. de Ensino de C\&T 
DE CLERCQ, L. ¿Qué es la web 2.0? In: GRANÉ, M., WILLEM, C. (Orgs.). Web 2.0: Nuevas formas de aprender e participar. Barcelona: Laertes Educacion, 2009, pp. 21-32.

FERNANDES, G. C.; ALVES, L. S.; OSAKA, O. T.; ANDRADE, T. R. O. O uso da tecnologia em prol da educação: Importância, benefícios e dificuldades encontradas por instituições de ensino e docentes com a integração novas tecnologias à educação. Saber digital, v. 6, n. 1, p. 140-148, 2013.

FERREIRA, G. M. S.; BOHADAN, E. D. B. Possibilidades e desafios do uso do Facebook na educação. In: PORTO, C.; SANTOS, E. Facebook e educação: publicar, curtir, compartilhar. Campina Grande: EDUEPB, 2014, pp. 255-274

FISHER, B. A. Interpersonal communication: pragmatics of human relationships. Nova lorque: Random House, 1987.

GROSSI, M. G. R.; LOPES, A. M.; JESUS, P. M.; GALVÃO, R. R. O. A utilização das tecnologias digitais de informação e Comunicação nas redes sociais pelos universitários Brasileiros. Texto Digital, v. 10, n. 1,2014 , p. 4-23.

HOUGHTON, L.; RUUTZ, A.; GREEN, W.; HIBBINS, R. I just do not have time for new ideas: resistance, resonance and micro-mobilisation in a teaching community of practice. Higher Education Research \& Development, v. 34, n. 1, p. 527-540, 2015.

JOHNSON, S. Emergence. The connected lives of ants, brains, cities and software. Penguin Books: London, 2001.

KAY, V. M.; ANDRADE, D. N. D. Ferramentas Web 2.0 para Atividades em Educação a Distância, utilizadas em conjunto com o Ambiente Virtual de Aprendizagem Moodle. Revista EaD \& Tecnologias Digitais na Educação, v. 2, n. 3, 2014.

KELLY, G. A. The psychology of personal constructs. New York: Norton, 1963.

KELLY, G. A. A brief introduction to personal construct theory. In: BANNISTER, D. (ed.). Perspectives in personal construct theory. London: Academic Press, 1970, p. 1-29.

LARA, T. Alfabetización digital desde el pensamiento crítico. In: GRANÉ, M., WILLEM, C. (Orgs.). Web 2.0: Nuevas formas de aprender e participar. Barcelona: Laertes Educacion, 2009, p. 107128.

LEÃO, M. B. C. Tecnologias na educação: uma abordagem crítica para uma atualização prática. Recife: UFRPE, 2011.

LEITE, B. S. M-Learning: o uso de dispositivos móveis como ferramenta didática no Ensino de Química. Revista Brasileira de Informática na Educação, v. 22, n. 3, p. 55-68, 2014.

LEITE, B. S. Tecnologias no Ensino de Química: teoria e prática na formação docente. Curitiba: Appris, 2015.

R. B. E. C. T., vol 8, núm. 4, set-dez.2015 ISSN - 1982-873X

DOI: Em andamento. 
LEITE, B. S.; LEÃO, M. B. C.; ANDRADE, S. A. Videocast: uma abordagem sobre pilhas eletrolíticas no ensino de química. Revista Tecnologias na Educação. v. 2, n. 1, p. 1-11, 2010.

LIMA, A. P. L. O uso de ferramentas da web 2.0 no compartilhamento de informação e conhecimento. Revista do Mestrado Profissional Gestão em Organizações Aprendentes, v. 3, n. 1, p. 128-139, 2014.

LIVINGSTONE, S. Las redes sociales online - una oportunidad con riesgos para adolescentes. In: GRANÉ, M., WILLEM, C. (Orgs.). Web 2.0: Nuevas formas de aprender e participar. Barcelona: Laertes Educacion, 2009, pp. 87-106.

LÜDKE, M.; ANDRÉ, M. E. D. A. Pesquisa em educação: abordagens qualitativas. São Paulo: EPU, 2012.

LUNDVALL, B. A. The University in the Learning Economy, 2002. Disponível em: <http://www.druid.dk/wp/pdf_files/02-06.pdf> Acesso em: 29 outubro 2014.

MARTIN, L. Expresiones políticas del internet social. Vdevivienda: un estudio de caso. In: GRANÉ, M., WILLEM, C. (Orgs.). Web 2.0: Nuevas formas de aprender e participar. Barcelona: Laertes Educacion, 2009, pp. 69-85.

MATTAR, J. Web 2.0 e redes sociais na educação. São Paulo: Artesanato Educacional, 2013.

MOREIRA, D. R.; DIAS, M. S. WEB 2.0 - A Web social. Revista CEPPG, v. 1, n. 20, p. 196-208, 2009.

MOREIRA, J. A.; JANUÁRIO, S. Redes sociais e educação: reflexões acerca do Facebook enquanto espaço de aprendizagem. In: PORTO, C.; SANTOS, E. (Orgs.) Facebook e educação: publicar, curtir, compartilhar. Campina Grande: EDUEPB, 2014, pp. 67-84.

MOREIRA, L.; RAMOS, A. Facebook na formação contínua de professores para o uso de tecnologias digitais. In: PORTO, C.; SANTOS, E. (Orgs.) Facebook e educação: publicar, curtir, compartilhar. Campina Grande: EDUEPB, 2014, pp. 313-328.

OLIVEIRA, E. B.; DUTRA, M. L. Um levantamento sobre do uso de ferramentas da Web 2.0 entre os estudantes da Ciência da Informação da Universidade Federal de Santa Catarina. Revista eletrônica de biblioteconomia e ciência da informação, v. 19, n. 39, p. 153-182, 2014.

O'REILLY, T. What is web 2.0. design patterns and business models for the next generation of software, $2005 . \quad$ Disponível em: <http://www.oreillynet.com/pub/a/oreilly/tim/news/2005/09/30/what-is-web-20.html> Acesso em: 07 maio 2014.

RECUERO, R. Redes sociais na internet. Porto Alegre: Sulina, 2009.

ROGERS, L. E. The meaning of relationship in relational communication. In: CONVILLE, R. L.; ROGERS, L. E. (Eds.). The meaning of "relationship" in interpersonal communication. Westport: Praeger, 1998.

314 DOI: Em andamento.

R. Bras. de Ensino de C\&T 
PORTO, C.; SANTOS, E. Facebook e educação: publicar, curtir, compartilhar. Campina Grande: EDUEPB, 2014.

PRIMO, A. Interação mediada por computador: comunicação, cibercultura, cognição. Porto Alegre: Sulina, 2007.

ROSA, R. Trabalho docente: dificuldades apontadas pelos professores no uso das tecnologias. Revista Encontro de Pesquisa em Educação, v. 1, n.1, p. 214-227, 2013.

SANTOS, F. C.; CYPRIANO, C. P. Blogs e Wikis: duas formas de colaboração em redes sociais. Ciência em Movimento, n. 26, p. 7-19, 2011.

SILVA, A. M. T. B. O Processo de Apropriação das Tecnologias na Prática Profissional dos Docentes da Área do Ensino das Ciências e Matemática: um estudo preliminar a partir da teoria das representações sociais. ALEXANDRIA Revista de Educação em Ciência e Tecnologia, v. 6, n. 2, p. 33-52, 2013.

SPIRO, R.; JEHNG, J. Cognitive flexibility, random access instruction and hypertext: theory and technology for the nonlinear and multi-dimensional traversal of complex subject matter. In: NIX, D.; SPIRO R. (Orgs.). The "handy project", new directions in multimedia instruction. New Jersey: Lawrence Erlbaum, 1990, pp. 163-205.

Bruno Silva Leite é licenciado em Química e Mestre em Ensino de Ciências pela Universidade Federal Rural de Pernambuco (UFRPE). Docente em Ensino de Química na Universidade Federal Rural de Pernambuco. E-mail: brunoleite@ufrpe.br

Marcelo Brito Carneiro Leão é licenciado em Química pela Universidade Federal Rural de Pernambuco (UFRPE). Doutor e Mestre em Química computacional pela Universidade Federal de Pernambuco. Pós-Doutor no uso das Tecnologias da Informação e Comunicação no Ensino de Ciências pela Universitat de Barcelona. É professor associado e Vice-Reitor da UFRPE. Bolsista de Produtividade DT do CNPq. E-mail: mbcleao@terra.com.br

DOI: Em andamento. 